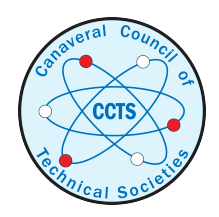

The Space Congress $®$ Proceedings

1987 (24th) Space - The Challenge, The

Commitment

Apr 1st, 8:00 AM

\title{
A Model for Enveloping Space Station Logistics Requirements
}

K. M. Seiser

Wyle Laboratories

R. E. Giuntini

Wyle Laboratories

Follow this and additional works at: https://commons.erau.edu/space-congress-proceedings

\section{Scholarly Commons Citation}

Seiser, K. M. and Giuntini, R. E., "A Model for Enveloping Space Station Logistics Requirements" (1987).

The Space Congress ${ }^{\circledR}$ Proceedings. 2.

https://commons.erau.edu/space-congress-proceedings/proceedings-1987-24th/session-4/2

This Event is brought to you for free and open access by the Conferences at Scholarly Commons. It has been accepted for inclusion in The Space Congress ${ }^{\circledR}$

Proceedings by an authorized administrator of Scholarly Commons. For more information, please contact commons@erau.edu.

EMBRYARDDLE Aeronautical University SCHOLARLY COMMONS 
A MODEL FOR ENVELOPING

SPACE STATION LOGISTICS REQUIREMENTS

By K. M. Seiser and Dr. R. E. Giuntini, Wyle Laboratories

ABSTRACT

Since the inception of the space station Customer Logistics study, it became apparent that a modeling process was needed to provide insight into the many sensitivities and relationships which exist among the numerous variables which impact Space station customer Accomodations and Logistics Support Requirements with regard to their assoclated design requirements. such a model would provide the necessary and timely support to the space station designers and planners during the program's early development. This paper will address the current design and operations of the space station in particular the Manufacturing and Technology Laboratory (MTL) which is the primary focus of the study and the model. Typical expertments planned for the MTL will be addressed as well as their on-orbit operational and logistical requirements. A detailed description of the model developed under the study along with some of its many applications for scoping space station Logistics Requirements will be presented.

\section{INTRODUCTION}

Space Commerclalization is a princlpal reason for the space station. space possess extremes of cold, ultravacuum, and microgravity all of which lend themselves to exploitation by hightechnology industrial processes that are very difficult and in some cases impossible to accomplish on earth. Many U.S. experiments have already been identified that have commercial potential. This is why three of the five presently envisioned space station habitable modules will either be dedicated to or be utilized to a high degree for materlals processing and, also, why NASA has planned a space commercialization organization which will consider and propose policies for the industrial uses of the space station. The market is apparently huge and has been estimated as approaching billions of dollars within the next few years. Due to this extremely large potential market, the space station Customer Logistics study was implemented. The objective of the study is to 1dentify logistics requirements necessary to support the entire spectrum of materials processing activities planned for the space station.
The U.S. Laboratory referred to as the Materials and Technology Laboratory (MTL) was the focus of the study. The European and Japanese Modules were not part of the initial study effort. There are many issues remaining to be resolved with respect to the policies regarding the operations of three laboratories and whether the U.S. lab will initially be a combined lab including life sciences as well as materials processing. The study was funded with NASA commercial funds and reflects a MTL dedicated to Materlals Processing in space (MPS) payload experiments. The effort is currently being broadened to include Life Sciences. Figure 1.0 shows the three space station laboratories. Two are designated as LABs and the third as JEM which is the Japanese Experiment Module.

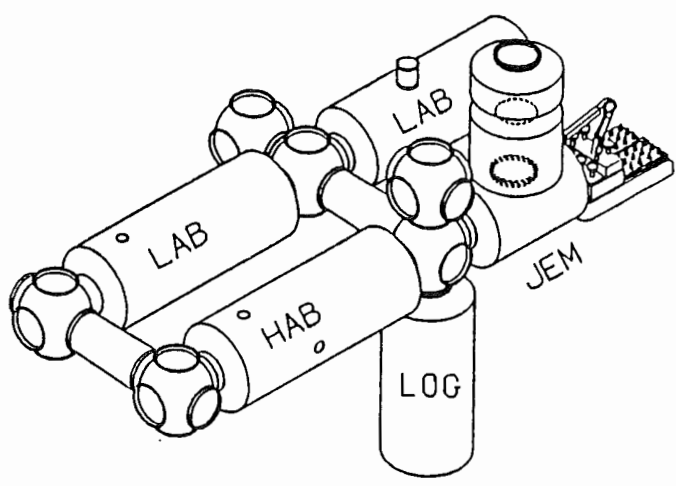

FIGURE 1.0

CURRENT SPACE STATION CONFIGURATION

THE MTL

A cut-away view of the current conceptual design of the MTL is provided in Figure 2.0. The MTL will support and house varlous materials processing facilities for baslc and applied research, experimentation, and materials production in the following scientific disciplines: (1) Biological Materials, (2) Combustion science, (3) Electronic Materials, (4) Fluids and Chemistry, (5) Glasses and Ceramics, and ( 6 ) Metals and Alloys. 


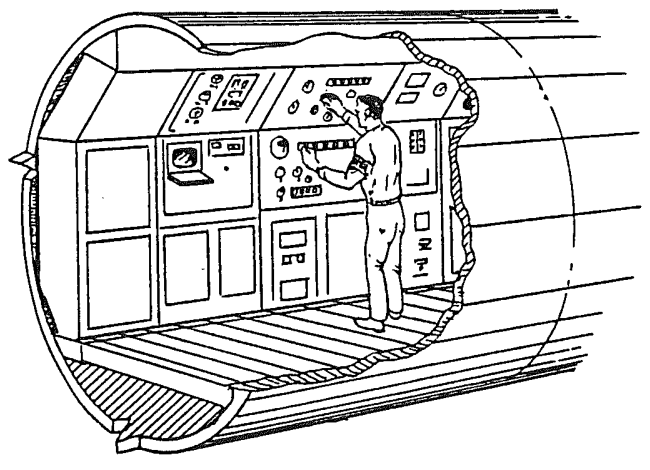

FIGURE 2.0

CURRENT CONCEPTUAL DESIGN OF THE MTL

Each experiment facllity referred to as a payload will be configured and integrated into one of two standard NASA racks; i.e. Single or Double racks. Illustrated in Figure 3.0 is an integrated double rack. The racks will provide the structural, electrical and fluid interface between the payload and the MTL. The racks will be integrated and tested on the ground before beling stored in the logistics module for transport to the station. once at the station, the rack will be removed from the logistics module and transferred to the MTL by crewmen, where it will be mounted in the designated rack space and the electrical, fluid and avionics interfaces will be connected to the MTL.

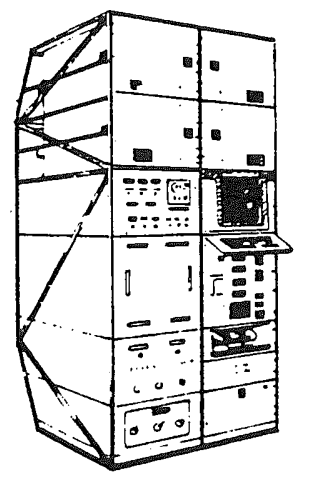

FIGURE 3.0

SPACE STATION DOUBLE RACK
For a payload to accomplish its research on-orbit a variety of requirements must be inet. For example, each experiment/ payload will require power to operate, a crewman to perform operational activities, input materials or samples, purge gases and/or liquids, as well as a variety of product characterization and payload support equipment. These requirements represent only a small subset of the customer's payload requirements for successful operation in the MTL.

Payloads returning to earth are disconnected from the MTL and transferred to the logistics module for the flight home. For terminology purposes, each set of payloads in the MTL is called a mission or mission set, and when a payload is "changed-out" a new mission set exists in the MTL.

\section{SPACE STATION MTL TRAFFIC}

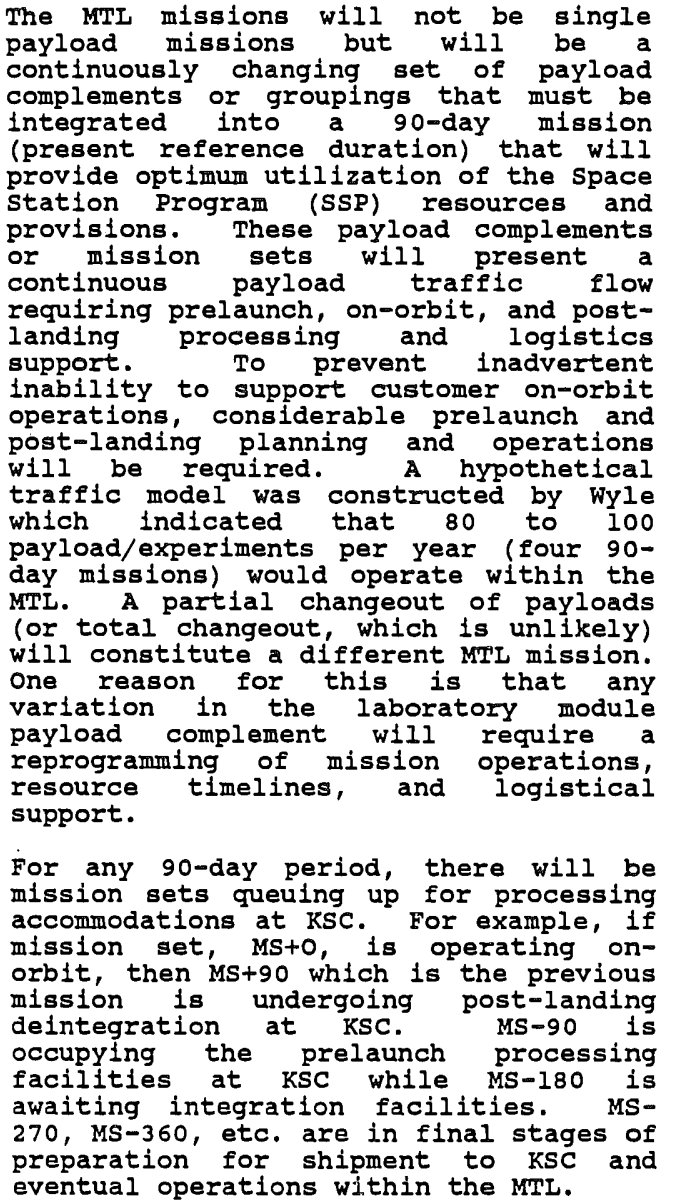


Payloads must be considered in mission sets or payload complements rather than individually since each is vying for a common set of Space station resources and provisions both on-orbit and on the ground. Their optimized on-orbit operational mix is what drives the ground operations - both prelaunch and post-landing.

Payload on-orbit operations consist of a set of tasks from preparation, setup, payload/experiment run, product characterization, cleanup and preparation for the next run. Each of the steps is identified and timelined as required. of particular significance is the product characterization which depending on the requirements could entail the use of a number of pieces of equipment and instruments and take considerable crew time. These items of equipment are termed characterization and support equipment.

\section{LOGISTICAL PERSPECTIVE}

To understand the full implications of the payload requirements for both ground and on-orbit operations, it is important to establish the logistical perspective. Logistics must be able to identify and plan for the entire spectrum of logistical requirements that must be satisfied in order to support ground and on-orbit operations.

To be able to accomplish on-orbit activities, any given payload will require as a minimum the following: (1) a set of support equipment, (2) a set of characterization equipment, (3) materials and samples, (4) gases of various types and, (5) liquids including water. The output of the processing activities results in products and wastes. The number of on-orbit payload operational run cycles (depends upon the payload complement of which this payload is but one of several) will determine the quantity of materials/samples, gases, and liquids consumed and the quantity or amount of products and wastes produced during any given mission.

This is conceptually illustrated in Figure 4.0, Logistics Considerations. The figure shows two basic equations as follows :

(1) Mass and Volume Up $=A+B+C+D$ $+E+F$

(2) Mass and Volume Down $=X \%(A)+Y \%$ (B) $+\mathrm{Z} \%$ (C) $+\mathrm{G}+\mathrm{H}$

The equations for identifying the mass and volume up and down indicate an inportant point. There are many items in addition to the payload themselves that must be considered and planned for to enable the payloads to carry out their on-orbit missions.

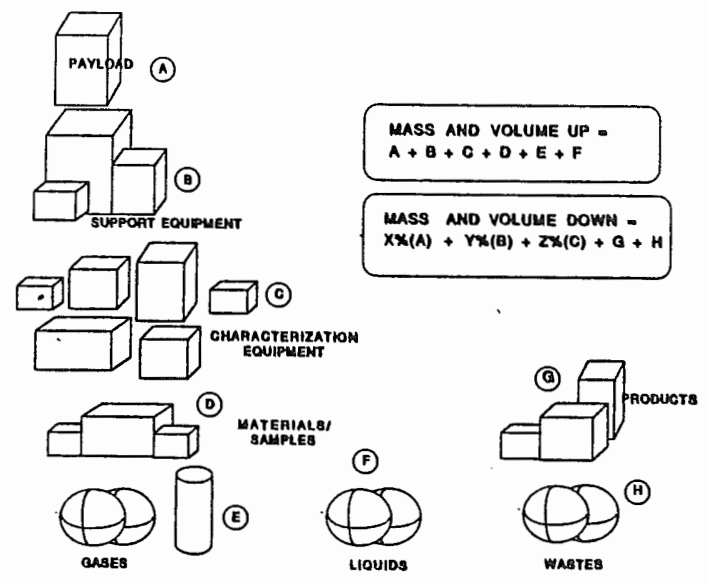

FIGURE 4:0

IOGISTICS CONSIDERATIONS

Another highly important logistical consideration is the amount of payload integration and processing time required to install, test, checkout, and prepare the payload, all other equipment, the sample materials, and tools/instruments for stowage aboard the logistics module. This aspect of logistics is extremely essential in establishing the overall time required to process not just a single payload but the entire payload mission set (several payloads). By knowing the overall processing time for the mission set, (1) the number of integration (prelaunch) rooms (2) the quantities of ground support and handling equipment, (3) the quantities and types of test and checkout equipment, (4) the quantities of tools of various types, and (5) the number of personnel can be determined. At every step in the processing timeline the various logistics and ground support items have been identified so that a demand for each can be established.

\section{THE PROBLEM}

NASA intends that the space station and the MTL to be "user friendly". This means it will be designed and built to accommodate and support the wide spectrum of tasks its many users want to accomplish. To obtain this objective from a logistic standpoint, the customer logistic study was tasked to identify the following logistics requirements: 
- Determine the amounc of mass and volume up to the space station and back to earth. This includes payloads, characterization and support equipment, samples materials, consumables (gases and fluids), and products and wastes derived from the payload operations.

- Determine the prelaunch ground operations necessary to support the onorbit operations. This includes ground processing of the payloads, equipment, and materials to prepare for launch, for on-orbit storage/ stowage.

- Determine the post-landing ground operations necessary to support the de-integration upon return from the space station. This includes deintegration of payloads, equipment, handing of wastes and samples, and refurbishment of items required for other missions.

- Determine the prelaunch processing facilities and the post-landing deintegration facilities necessary to support the space station missions. This includes size of integration and de-integration rooms and their respeciive outfitting as well as the number of each.

To identify these logistical requirements requires the solution of the onorbit operational problem which can be stated as follows:

- Given a MPL facility of designated size, a designated rack size (single and double) of known capacity, an allocated amoune of power, an allocared heat rejection capacity, an allocated venting capability, an allocated number of crew hours per day to support user payloads, etc., and furcher, given that there is an identilied number of representative payload/experimenis each requiring specific usage of tine MTL resources identifled above and. recognizing that the MTL must accomiuodate groupings of feasible combinations of payloads referred to as mission sets, then determine the on-orbit requirements to satisfy the entire population of Space station MIL mission requiremenes.

The solution of the logistical requirements is a fallour of the optimized onorbit operations. The problem is compounded further by recognition that the MTI facility resources (above) are, at this time, not fixed and are assumed to be variables. The problem becomes one of working multiple problem solutions and providing NASA with ranges of numbers on the variables rather than single numbers.
Therefore, a modeling technique was developed to envelop space station logistical requirements given various MIL resources. In working these problems, we routinely have derived solutions under various MTL size assumptions, rack size and availability assumptions, range of power assumptions, a range of crew hours per day assumptions, etc. to determir sensitivity to changes in these variables and others.

\section{THE MODELING PROCESS}

The model provides for the enveloping of MTL logistical requirements to study the sensitivity of integrated MTL mission requirements to:
(1) Size of the mission
(2) Duration of the mission
(3) Crew hours per day
(4) Level of characterization
(5) Etc.

Each set of variables utilized by the model is referred to as a path. The technique developed to envelop MTI Logistics Requirements is illustrated in Figure 5.0. The technique is based on two-different on-orbit scheduling methods. Method \#I schedules the payloads in the mission to receive only a minimum number of on-orbit runs based on limited resources during space station IOC. This method will allow the model to identify the minimum bound on MTL logistics requirements. The maximum bound is thus determined utilizing scheduling Method \#2 which will schedule the payloads based on an optimum maximum number of runs.

The first step the model performs is the identification of candidate MTI missions. This is done by identifying the number of racks required by each candidate payload for the MTL. The level of characterization is set and the model identifies the amount of characterization and support equipment required. The number of racks utilized by this equipment is then subtracted from the number of racks for the total mission. Thus, the number of racks allocated to payloads is identified and the model will compute all possible combinations of candidate mission sets. A random sample population of the hundreds/thousands of candidate mission sets is selected. The size of the sample population selected is dependent on the number of mission sets generated. A random sample population is selected due to the computer time and cost associated with scheduling all of the candidate missions. 


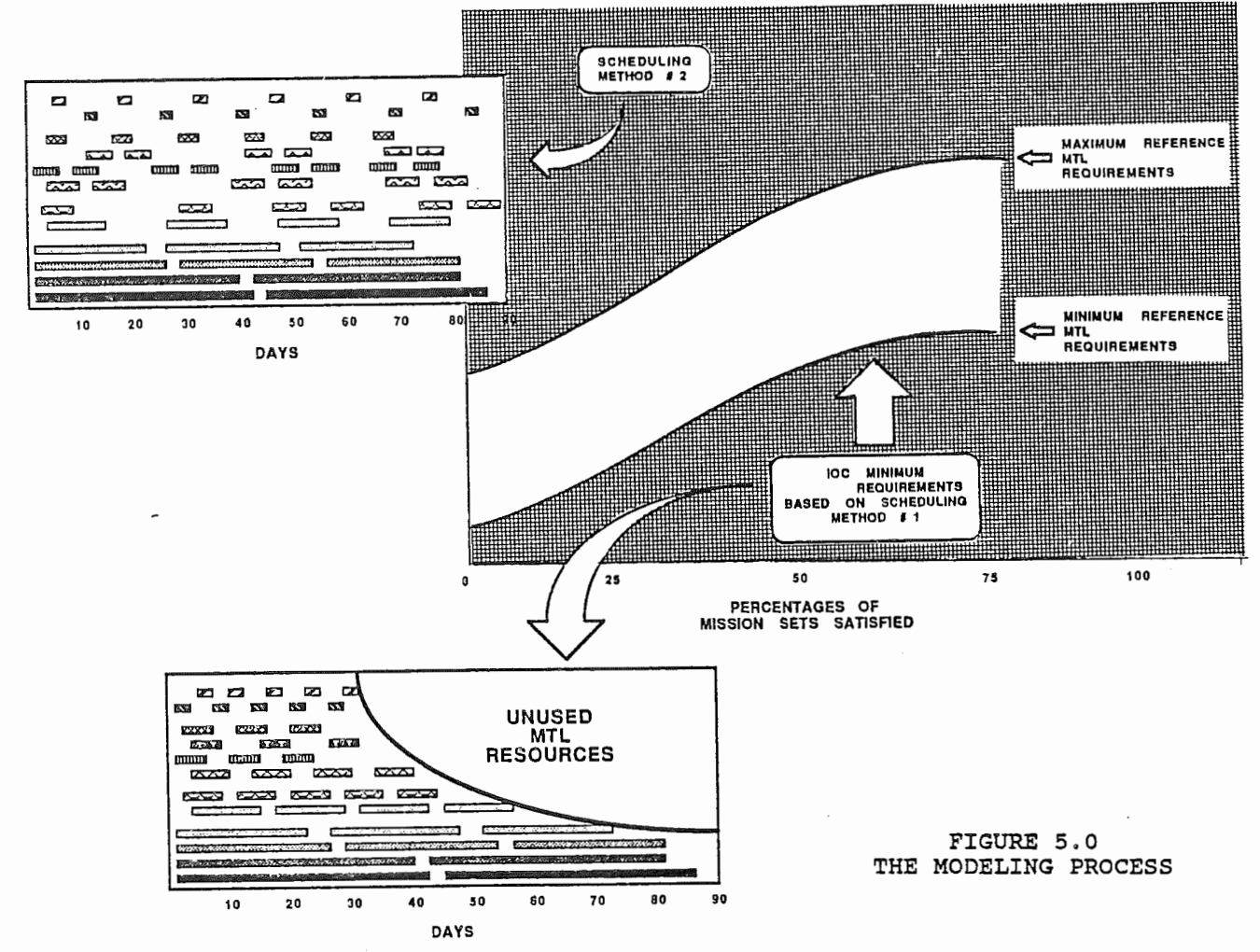

The model will now proceed to schedule the missions to deternine the number of on-orbit runs based on allocated amounts of:

\section{(1) Power}

(2) Heat rejection

(3) Crew hour's per day

(4) Micrograviey disiurbance level

(5) Etc.

These corstrainis are utilized in both scheduling metnods. As stared earlier, scheduling Method \#1 identifies IOC mininum logisical requirements by scheduling each payload to receive only a minimuin number of runs per mission. This will result in unused MTI resources, but will identify the minimum bound on the logistics envelop. This technique is illustrated in Figure 6.0 .

Since all the payloads in the mission would like to receive as many runs as possible the maximum number of runs for each payload is not defined. Thus, a problem trequenty occurs in scheduling which is 11lustrated in Figure 7.0 .

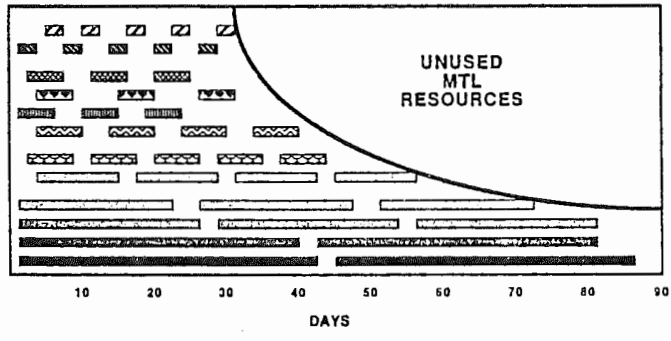

FIGURE 6.0 SCHEDULING METHOD \#I

Scheduling without payload maximum runs may result in some payloads receiving a large number of runs resulting in insufficient runs for payloads which are scheduled later. without a maximum number of runs to stop the scheduling of that payload, it utilizes a large amount of valuable MTL resources. Thus, by the time the last payload is to be scheduled, very little resources remain and the payload receives very few runs. To overcome this problem, a technique was developed to identify the optimum maximurn number of runs for each payload in the mission. 


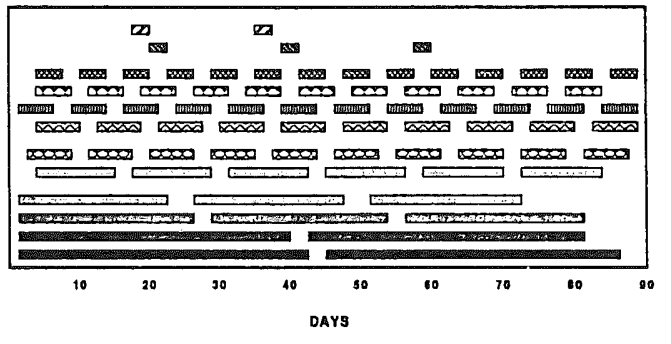

FIGURE 7.0

A PROBLEM IN SCHEDULING

Before the technique can be discussed, two terms must be defined:

(1) Crew utilization

(2) Percent efficiency

\section{CREW UTILIZATION}

CREW UTILIZATION = $\frac{\text { Total Crew Time Used }}{\text { Total Crew Time Available }}=\frac{\text { CTU }}{\text { CTA }}$

CTU $=\sum_{I=1}^{N} \sum_{J=1}^{\text {Runs }}$

(Runs $(I, J) *(C T(I))$

where,

Runs $(I, J)$ is the number of runs for payload $I$

CT (I) is the total crew time

required for one run of payload I

CTA $=\left[\begin{array}{l}\text { Number of } \\ \text { days in } \\ \text { the mission }\end{array}\right] *\left[\begin{array}{l}\text { Crew hours } \\ \text { available per } \\ \text { day }\end{array}\right]$

PERCENT EFFICIENCY

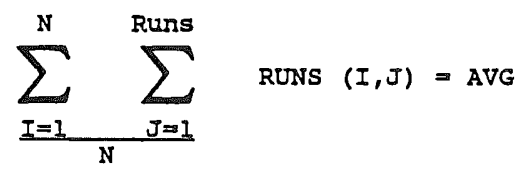

AVG $=$ Average number of runs for each payload in the mission

PERCENT INEFFICIENCY =

Max Run - Avg * 100 Max Run

thus,

PERCENT EFFICIENCY $=$

[1 - Percent Inefficiecy]
The methodology developed to identify the optimum maximum number of runs for the payloads in the missions is best illustrated by way of Figure 8.0. The first step in this process is to arbitrarily set a maximum number of runs for the missions to be scheduled under the first set of constraints, one being $x$ crew hours/day. This maximum number of runs will instruct the program to stop scheduling payload $X$ when it has received this set maximum number of runs. The missions are then scheduled based on the constraints (i.e. power, heat rejection, microgravity level, crew time etc.) and the number of runs for each payload in the mission is tracked. If all the payloads in the missions scheduled under this first set of constraints received the maximum number of runs or close to this value (i.e. percent inefficiency is low) then the crew utilization is calculated for the missions. If this crew utilization can be increased then the maximum number of runs is increased and the missions are rescheduled. However, if the percent inefflclency is to high then the maximum number of runs is decreased and the missions rescheduled. Eventually a maximum number of runs will be obtained in which the crew utilization is sufficiently high and the percent inefficlency low. This calculated crew utilization becomes the target for the remaining paths or sets of constraints to schedule the missions. Thus, the process is repeated to identify the maximum number of runs required to obtain the target crew utilization while the percent inefficlency is held low.

The output of this process determines the optimum between the maximum number of runs, crew utilization and percent efficlency for the missions under varlous sets of constraints such as:

(1) Mission size

(2) Length of the mission

(3) Crew hours per day

(4) Microgravity levels

(5) Etc.

Provided in Figure 9.0 is the output of this process for finding the optimum for a mission of 45 days in length with 25 hours per day of crew time, limited characterization and 23 single racks. The maximum number of runs for the missions was increased from 2 to 20 and the crew utilization and percent efficiency calculated. As can be seen from the graph as the maximum number of runs increases, the crew utilization increases, the percent efficiency decreases and the optimum is found as the point of intersection between the two Iines: crew utilization and percent 


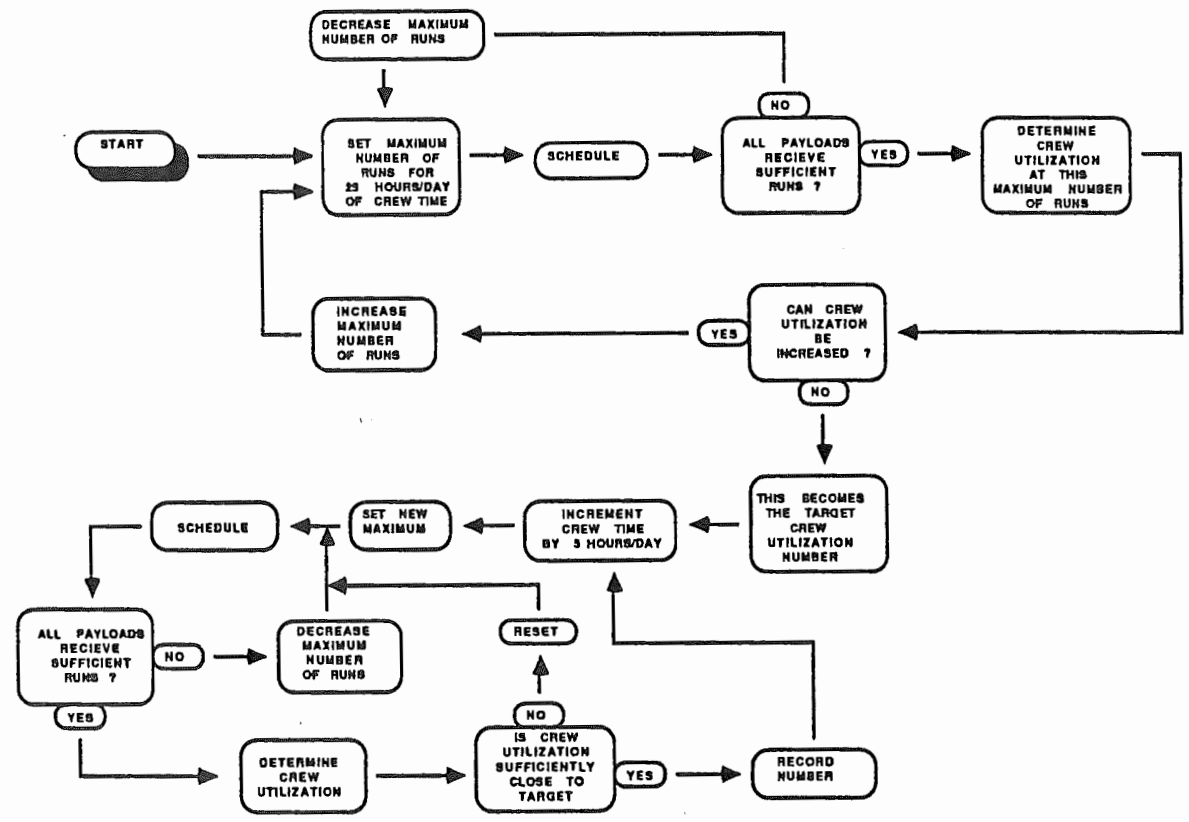

FIGURE 8.0

METHODOLOGY DEVELOPED TO IDENTIFY

THE OPTIMUM MAXIMUM NUMBER OF RUNS

CREW UTILIZATION SS SCHEDULING

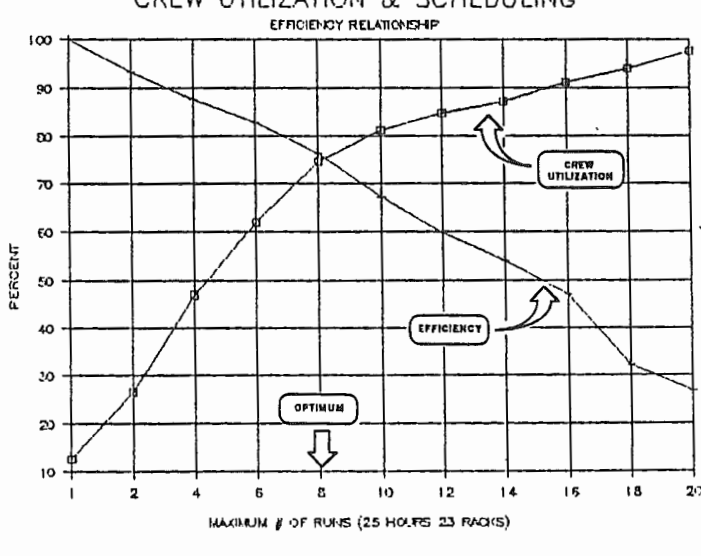

FIGURE 9.0

GRAPH OF CREW UTILIZATION VERSUS PERCENT EFFICIENCY efficiency. Conversely to prove their intersection reprresents the optinum, consider the graph of crew utilization vs. percent ineficiency, Floure 10.0 . First fit a polynomial to each of these lines and take the first derivative with respect to the maximum number of runs. Set these two equations equal and solve for $x$. This $x$ will represent the optimum maximum number of runs. Intuitively, the optimum is the maximum distance between the two lines as illustrated in the figure. Thus, with this optimum number of runs identified, the model proceeds to schedule the mission sets under the stated constraints. Ensuring that no payload in the mission recieves more than the maximum number of runs for the mission. This scheduling method allows identification of the upper or maximum bound on the logistics requirements envelop. 
CREW UTILIZATION \& SCHEDULING

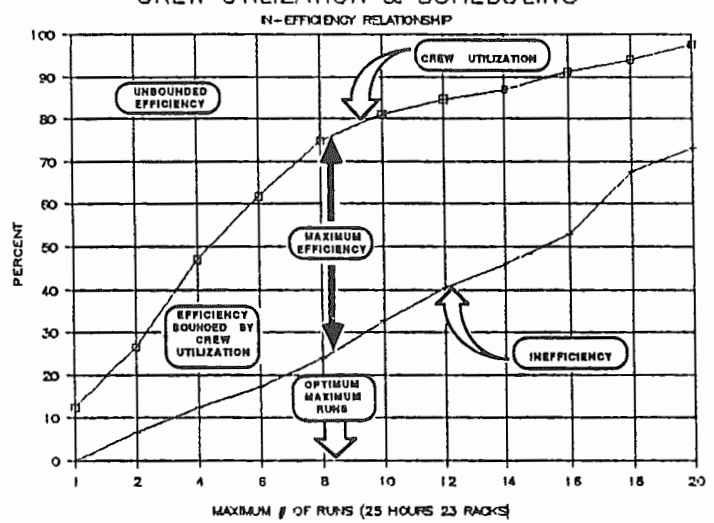

FIGURE 10.0

GRAPH OF CREW UTILIZATION VERSUS PERCENT INEFFICIENCY

The model has sufficiently solved the on-orbit operational problem and will now proceed to envelop the MTL and Space station Program logistical requirements.
To illustrate this process, consider the logistical requirement (task) of identifying/ enveloping the amount of consumables (fluids and gases) required by a mission. The methodology and technique utilized by the model is illustrated in Figure 11.0 .

From the multitude of missions generated and scheduled under various constratins or paths a mission is selected for analyses. The number of runs for each payload in the mission is identified from the schedule and multiplied by the total amount of consumables required for one payload run. This amount of consumables was derived from the space Station Customer Logistics data base and includes the consumables for the payload plus the consumables required by the baseline set of characterization and support equipment for that payload. Consumables are broken out into several categorles such as: water, $\mathrm{N}_{2}, \mathrm{O}_{2}, \mathrm{Ar}$, etc. The consumables are summed for that specific mission and another mission scheduled under the same constraints (Path) is selected. The process of identifying consumables required for each mlssion is repeated until all missions under that Path have been analyzed. The consumables required

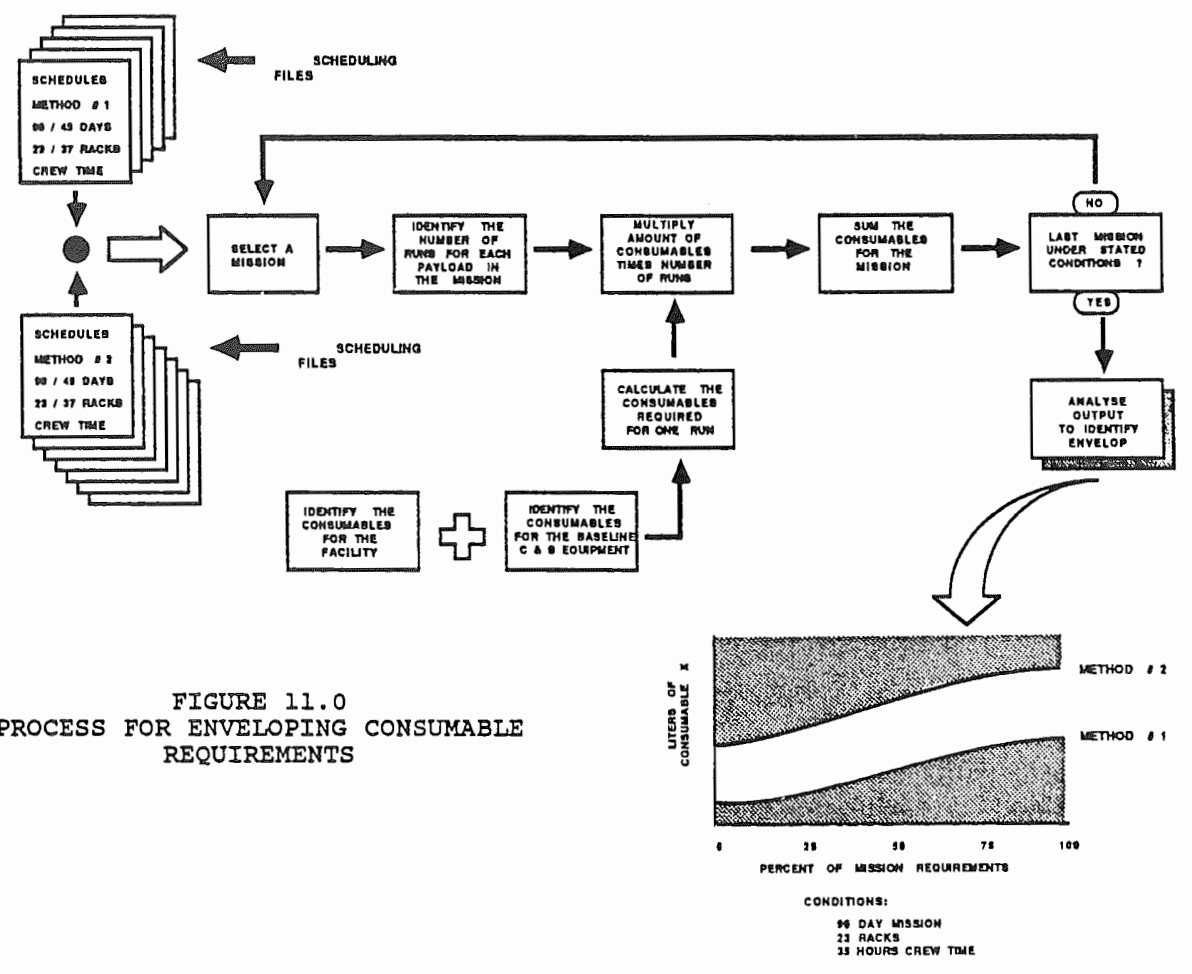


for each Path are then analyzed and cumulative distribution profiles developed. These cumulative distribution profiles identify the amount of a consumable $X$ required to satisfy a percentage of the missions under Path $Y$ constraints. The process is then repeated for the remaining paths. The output will identify an envelop of MTL consumables required based on minimum IOC requirements as the lower bound and maximum requirements beyond IOC as the upper bound. A typical requirements envelop developed for the consumable water, has been provided in Figure 12.0 . The graph depicts the minimum amount of water required for the MTL at space Station IOC and the maximum amount of water required based on the bounds imposed in the model (i.e. crew time, power to the MTL, size of the mission etc.).

45 DAYS 23 RACKS

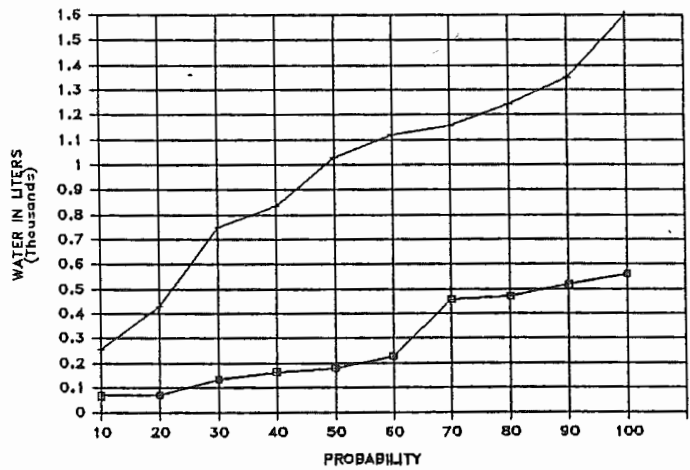

FIGURE 12.0

ENVELOP OF WATER REQUIREMENTS

During any one given analysis the model will develop thousands of schedules to produce the various envelopes. Thus, these envelopes allow for the identification of logistics requirements under various sets of constraints or Space station provisions. Furthermore, the model is utilized to study the sensitivity of integrated mission logistics requirements to the various paths.

\section{SUMMARY}

The model developed under the space station Customer Logistics study has proven extremely successful in identifying an envelop on Logistics Requirements. While the example given herein, illustrated the technique for identifying consumable requirements, the same basic process is applied to identify ground processing requirements (1.e. number of integration rooms, amount of equipment, de-integration facility requirements, etc.). Currently the model addresses logistics requirements for MTL payloads only, but is being expanded to address various MTL operational and design considerations as well. The current data base is also being expanded to incorporate life science payloads into the model. While the focus of the model is on MTI payloads, it has been shown by the study team that this technique is easily adaptable for use in optimizing and enveloping the operational and logistics requirements for the entire space station.

\section{ACKNOWLEDGEMENTS}

Many individuals within NASA and Wyle Laboratories contributed to the Customer Logistics Program. The authors are particularly indebted to $M r$. R. C. Jordan, III, and Mr. G. A. Opresko, Study Managers at the NASA/RSC Space Station Iogistics office, who have supported the program from its inception. The authors also acknowledge the valuable contributions of the Wyle study team.

\section{NOMENCLATURE}

IOC

Kennedy space center

MPS Materials processing in space

MTL Manufacturing and Technology Laboratory

NASA National Aeronautics and Space Adminisiration

SSP Space Station Program 